\title{
Zinc oxide nanoparticle-mediated changes in photosynthetic efficiency and antioxidant system of tomato plants
}

\author{
M. FAIZAN*, A. FARAZ , M. YUSUF*, S.T. KHAN ${ }^{* *}$, and S. HAYAT ${ }^{*,+}$ \\ Plant Physiology and Biochemistry Section, Department of Botany, Aligarh Muslim University, Aligarh, 202002, India* \\ DNA Research Chair, Zoology Department, College of Science, King Saud University, Riyadh 11451, Saudi Arabia**
}

\begin{abstract}
The present study was carried out to assess the role of zinc oxide nanoparticles (ZnO-NPs) in tomato plants on growth, photosynthetic efficiency, and antioxidant system. At 20-d stage of growth, roots of tomato plants were dipped into 0,2 , 4,8 , or $16 \mathrm{mg}(\mathrm{ZnO}-\mathrm{NPs}) \mathrm{L}^{-1}$ for 15,30 , and $45 \mathrm{~min}$ and then seedlings were transplanted in their respective cups and allowed to grow under natural environmental conditions. At 45-d stage of growth, the $\mathrm{ZnO}-\mathrm{NPs}$ treatments significantly increased growth, photosynthetic efficiency together with activities of carbonic anhydrase and antioxidant systems in a concentration- and duration-dependent manner. Moreover, the treatment by $8 \mathrm{mg}(\mathrm{ZnO}-\mathrm{NPs}) \mathrm{L}^{-1}$ for $30 \mathrm{~min}$ proved to be the most effective and resulted in maximum activities of antioxidant enzymes, proline accumulation and the photosynthetic rate. We concluded that presence of ZnO-NPs improved the antioxidant systems and speeded up proline accumulation that could provide stability to plants and improved photosynthetic efficiency.
\end{abstract}

Additional key words: antioxidant enzyme; gas exchange; growth; micronutrient.

\section{Introduction}

Naturally occurring or engineered materials with at least one dimension and less than $100 \mathrm{~nm}$ in size are called nanomaterials. These nanomaterials are also characterized by a very high surface area to volume ratio contributing to their unique physio-chemical properties. It is estimated that more than 12,480 commercial products use nanomaterials including biological systems (Poma and Di Giorgio 2008, Berube et al. 2010). Since such materials are being extensively used, their global production has also increased dramatically, making it immensely important to monitor a response of living systems to such material exposure. Limited reports are available dealing with the effect of nanomaterials on plants and related ecosystems (Bernhardt et al. 2010). Although plants and microbes are continuously exposed to naturally occurring nanomaterials, exposure to engineered nanomaterials is relatively new and requires appropriate attention (Chinnamuthu and Boopathi 2009).
In the last decade, various researchers showed that nanomaterials affect plant growth and development and assessed its use in sustainable agriculture practices. Castiglione and Cremonini (2009) reported that effect of NPs can be beneficial or harmful to plants depending on the type of nanomaterials used and their mode of application. Studies have demonstrated the uptake of NPs by different plants led to their accumulation in subcellular locations (Wang et al. 2012, Schwab et al. 2016), to alterations of various physiological processes, and induced plant growth and development (Garcia-Sanchez 2015, Ge et al. 2012). Moreover, Nair et al. (2011) revealed that silica-NPs induced seed germination, whereas the treatment with cadmium-selenide quantum dots restricted the germination. Lin and Xing (2007) showed that the higher concentrations of nano-sized $\mathrm{Zn}(35 \mathrm{~nm})$ and $\mathrm{ZnO}$ $(20 \mathrm{~nm})$ inhibited the germination in ryegrass and corn, respectively. In addition to this, Ma et al. (2010) reported

\footnotetext{
Received 5 August 2016, accepted 16 December 2016, published as online-first 17 March 2017.

${ }^{+}$Corresponding author; email: shayat@lycos.com

Abbreviations: ASH-GSH cycles - glutathione-ascorbate cycle; CA - carbonic anhydrase; CAT - catalase; $\mathrm{CeO}_{2}-\mathrm{NPs}$ - cerium oxide nanoparticles; $C_{\mathrm{i}}$ - intercellular $\mathrm{CO}_{2}$ concentration; DAS - days after sowing; DDW - double distilled water; $E$ - transpiration rate; $g_{\mathrm{s}}$ - stomatal conductance; LSD - least significant difference; NPs - nanoparticles; NR - nitrate reductase; $P_{\mathrm{N}}$ - net photosynthetic rate; $\mathrm{POX}$ - peroxidase; $\mathrm{ROS}$ - reactive oxygen species; $\mathrm{SiO}_{2}-\mathrm{NPs}$ - silicon oxide nanoparticles; $\mathrm{SOD}$ - superoxide dismutase; SPAD - soil and plant analysis development; ZnO-NPs - zinc oxide nanoparticles.

Acknowledgements: M. Faizan and A. Faraz gratefully acknowledge the University Grants Commission (UGC), New Delhi, India for rendering a financial support in the form of UGC Non-NET Fellowship under PhD. program.
} 
that at particular concentration of $\mathrm{CeO}_{2}$ NPs did not induce any changes in root elongation, whereas $\mathrm{La}_{2} \mathrm{O}_{3}, \mathrm{Gd}_{2} \mathrm{O}_{3}$, and $\mathrm{Yb}_{2} \mathrm{O}_{3}$ affected the root growth. The inhibitory effects of these NPs were observed at different stages of growth. The global production of $\mathrm{ZnO}-\mathrm{NPs}$ is ever increasing to its extensive use in various industrial products (Piccinno et al. 2010) making it one of the most produced NPs. These NPs end up in various habitats including soil (Keller et al. 2013). Hence, the effect of these NPs on plants and soil ecosystem should be studied. Therefore, the phytotoxic behaviour of the NPs needs to be addressed scientifically before utilizing them for agriculture practices. On the other hand, Oancea et al. (2009) believed that controlled release of active plant growth stimulators and other chemicals encapsulated in nanocomposites made of layered double hydroxides (anionic clays) could be feasible option for organic agriculture. Uptake of nanoparticles by plants,

\section{Materials and methods}

Plant materials: The seeds of tomato (Lycopersicon esculentum L. cv. PKM-1) were procured from National Seed Corporation Ltd., New Delhi, India. The seeds of healthy looking and uniform size were surface-sterilized with $1 \%$ sodium hypochlorite solution for $10 \mathrm{~min}$, followed by repeated washing with double distilled water (DDW).

Source of nanoparticles: Zinc oxide nanoparticles ( $\mathrm{ZnO}-$ NPs) were synthesized and characterized as described by Khan et al. (2016). Characterization refers to the study of material features, such as its composition, structure, and various properties (physical, electrical, magnetic, etc.) There is a number of techniques which are used in the process of characterization, such as separation, microscopy, spectroscopy, etc. (Fabrega et al. 2011).

Required quantity $\left(2,4,8\right.$, or $\left.16 \mathrm{mg} \mathrm{L}^{-1}\right)$ of $\mathrm{ZnO}-\mathrm{NPs}$ was dissolved in $10 \mathrm{ml}$ of DDW in a $100 \mathrm{ml}$ volumetric flask and final volume was made up to the mark by using deionised water. Surfactant (Tween-20) was used prior to treatment. The roots were washed with $0.01 \%$ Tween 20 for $1 \mathrm{~min}$ before dipping in NPs.

Treatment pattern and experimental design: The experiment was conducted under randomized block design with 75 plastic cups ( $350 \mathrm{~mL}$ in size). The sterilized seeds were sown in a plastic tray $(28 \times 40 \times 16 \mathrm{~cm})$ filled with an equal quantity of sandy loam soil mixed with farmyard manure in a ratio of 6:1. At $20 \mathrm{~d}$ after sowing (DAS), seedlings were transplanted to plastic cups $(350 \mathrm{~mL}$ in size) filled with acid-washed sand allowed to germinate under natural environmental conditions in the net house of Department of Botany, Aligarh Muslim University, Aligarh, India. Cups $(n=75)$ were divided into 3 groups for 15,30 , and 45 min-treatment duration, whereas 5 sets in each group represented $100 \mathrm{ml}$ of 0 (control), 2, 4, 8, or $16 \mathrm{mg}(\mathrm{ZnO}$ NPs) $\mathrm{L}^{-1}$, respectively, and each treatment was replicated their translocation, and effect on plants were reported by various researchers (Dietz and Herth 2011). Moreover, positive effects of nanoparticles in various plants are shown in various species, such as peanut (Parasad et al. 2012), wheat (Ramesh et al. 2014), and cotton (Venkatachalam et al. 2017).

With the above cited reports regarding the NPs in general and ZnO-NPs in particular, the present study was designed to characterise the plant profile in terms of growth biomarkers, photosynthetic efficiency, and antioxidants capacity of tomato plants with different concentrations of $\mathrm{ZnO}-\mathrm{NPs}$ applied through roots, which has not been reported earlier. Moreover, transplantation is a common practice for vegetables, including tomato. Therefore, dipping of roots in $\mathrm{ZnO}-\mathrm{NPs}$ at the time of transplantation could be established as an effective mode of nanoparticles application for vegetables.

five times. All the seedlings were transplanted in their cups and allowed to grow under natural environmental conditions with the supply of full nutrient solutions (Hewitt 1966) on alternate days. On 45 DAS, the plants in all the sets of each group were assessed for various growth and leaf gas-exchange traits as well as biochemical parameters.

Determination of growth biomarkers and leaf area: The growth biomarkers [shoot and root length, shoot and root fresh (FM) and dry mass (DM)] were determined by the method followed by Khan et al. (2015).

The leaf area was measured by using a portable leaf area meter (ADC Bioscientific, UK).

Determination of chlorophyll (SPAD value): The SPAD values of chlorophyll $(\mathrm{Chl})$ in the leaves were measured under natural conditions by using the SPAD chlorophyll meter (SPAD-502; Konica, Minolta Sensing, Inc., Japan).

Determination of leaf gas-exchange traits: Photosynthetic traits were determined on the third fully expanded attached leaves before collection of leaf sample for other parameters between 11:00 and 12:00 h by using an infra-red gas analyzer (IRGA) portable photosynthetic system (LI-COR 6400, LI-COR, Lincoln, NE, USA). In order to measure the net photosynthetic rate $\left(P_{\mathrm{N}}\right)$ and its related attributes [stomatal conductance $\left(g_{\mathrm{s}}\right)$, intercellular $\mathrm{CO}_{2}$ concentration $\left(C_{\mathrm{i}}\right)$, transpiration rate $\left.(E)\right]$, the air temperature, relative humidity, $\mathrm{CO}_{2}$ concentration, and PPFD were maintained at $25^{\circ} \mathrm{C}, 85 \%, 600 \mu \mathrm{mol} \mathrm{mol}^{-1}$, and $800 \mu \mathrm{mol} \mathrm{mol} \mathrm{m}^{-2} \mathrm{~s}^{-1}$, respectively.

Biochemical analysis: Fresh leaves (1 g) were weighed and homogenized in a cold extraction buffer $(70 \mathrm{mM}$ phosphate buffer; $\mathrm{pH} 7.0,1 \mathrm{mM}$ EDTA, $1 \mathrm{mM}$ phenylmethylsulfonyl fluoride (PMSF), $0.5 \%$ Triton $X-100$, and 
2\% polyvinylpyrrolidone (PVP) with the help of a precooled mortar and pestle. The homogenate was centrifuged at $12,000 \times g$ for $20 \mathrm{~min}$ at $4^{\circ} \mathrm{C}$ and the supernatant was stored at $-20^{\circ} \mathrm{C}$. This supernatant was utilized for analysis of a protein content and activities of antioxidant enzymes catalase (CAT), peroxidase (POX) and superoxide dismutase (SOD).

The total protein content of leaves was determined by the method followed by Bradford (1976). The Bradford reagent $(2 \mathrm{ml})$ was added to $100 \mu \mathrm{l}$ of supernatant and mixed gently and thoroughly. The samples were incubated at $25^{\circ} \mathrm{C}$ for $5-10 \mathrm{~min}$ and the absorbance at $595 \mathrm{~nm}$ measured by a spectrophotometer (Spectronic 20D, Milton Roy, Rochester, NY). A graph of absorbance vs. different known concentrations for standard solutions of bovine serum albumin (BSA) was plotted and a standard linear equation was derived. The amount of protein in the samples was calculated from the standard linear equation. The amount of protein was expressed as $\mathrm{mg} \mathrm{g}^{-1}(\mathrm{FM})$.

The activity of carbonic anhydrase (CA, 4.2.1.1) in the leaves was measured following the method described by Dwivedi and Randhawa (1974). The leaf samples were cut into small pieces in cysteine hydrochloride solution. The leaf samples were blotted and transferred in a test tube, followed by the addition of phosphate buffer $(\mathrm{pH} 6.8)$, $0.2 \mathrm{M} \mathrm{NaHCO}_{3}$, bromothymol blue, and the methyl red indicator, at the last. This reaction was titrated against $0.5 \mathrm{~N} \mathrm{HCl}$. The activity of enzyme was expressed on the

\section{Results}

Growth biomarkers: Plants grown with $\mathrm{ZnO}-\mathrm{NPs}$ of the average size of $35 \mathrm{~nm}$, irrespective of durations and treatments, showed a positive increase in growth biomarkers (length of shoot and root, FM and DM of shoots and roots, and leaf area) in comparison with control plants. Moreover, the maximum increase of growth parameters was reported in the plants with the roots exposed to $8 \mathrm{mg}(\mathrm{ZnO}-\mathrm{NPs}) \mathrm{L}^{-1}$ of for $30 \mathrm{~min}$ before transplantation; values for shoot length (35.8\%), root length (28.6\%), shoot FM and DM (21.9 and 27.6\%, respectively), FM and DM of roots (19.9 and $27.7 \%$, respectively), and leaf area $(27.9 \%)$ were higher than their respective controls (Figs. $1,2 A)$. The pattern of growth parameters after 30-min root dipping followed for various concentrations an order of $8>16>4>2>0 \mathrm{mg}(\mathrm{ZnO}-\mathrm{NPs}) \mathrm{L}^{-1}$.

Chl content (SPAD units): All the treatments under different durations of exposure showed an increase in the Chl content (SPAD) in the plants and their response was both concentration- and duration-dependent (Fig. 2B). Out of various treatments by $\mathrm{ZnO}-\mathrm{NPs}$ and after 30-min exposure of roots before transplantation, the concentration of basis of fresh mass in the form of $\operatorname{mol}\left(\mathrm{CO}_{2}\right) \mathrm{g}^{-1}(\mathrm{FM}) \mathrm{s}^{-1}$. The activity of nitrate reductase (NR, 1.6.6.1) was measured following the method of Jaworski (1971). The fresh leaf samples were cut into small pieces and transferred to plastic vials, containing phosphate buffer ( $\mathrm{pH} 7.5), \mathrm{KNO}_{3}$, and isopropanol, and incubated at $30^{\circ} \mathrm{C}$ for $2 \mathrm{~h}$. After incubation, sulfanilamide and N-1-naphthylethylenediamine hydrochloride solutions were added. The absorbance was read at $540 \mathrm{~nm}$ on a spectrophotometer (Spectronic 20D; Milton Roy, USA). The activity of enzyme was expressed on the basis of fresh mass in the form of $\mathrm{nM}\left(\mathrm{NO}_{2}\right) \mathrm{g}^{-1}(\mathrm{FM}) \mathrm{s}^{-1}$.

The activities of various enzymes such as catalase (CAT, 1.11.1.6), peroxidase (POX, 1.11.1.7), superoxide dismutase (SOD, 1.15.1.1) and contents of proline were analysed as described in our previous study (Khan et al. 2015). The activity of enzyme was expressed on the basis of fresh mass in the form $\mathrm{nM}\left(\mathrm{H}_{2} \mathrm{O}_{2}\right)$ decomposed $\mathrm{g}^{-1}(\mathrm{FM})$ for CAT, $\mathrm{U} \mathrm{g}^{-1}(\mathrm{FM})$ for POX, $\mathrm{U} \mathrm{g}^{-1}(\mathrm{FM})$ for SOD and $\mathrm{mg} \mathrm{g}^{-1}(\mathrm{FM})$ for protein.

Statistical analysis: Data were statistically analyzed using SPSS, 17.0 for Windows (SPSS, Chicago, IL, USA). Standard error was calculated and analysis of variance $(A N O V A)$ was performed on the data with 5 replicates to determine the least significance difference (LSD) between treatment means with the level of significance at $p \leq 0.05$.

$8 \mathrm{mg}(\mathrm{ZnO}-\mathrm{NPs}) \mathrm{L}^{-1}$ showed a maximum value for the Chl content over all the other treatments and durations.

Leaf gas-exchange traits: The plants with the roots dipped for $30 \mathrm{~min}$ in $\mathrm{ZnO}-\mathrm{NPs}\left(8 \mathrm{mg} \mathrm{L}^{-1}\right)$ before transplantation showed the highest values of $P_{\mathrm{N}}(50.7 \%), g_{\mathrm{s}}$ $(34.4 \%), C_{\mathrm{i}}(27.9 \%)$, and $E(32.0 \%)$ in comparison with their control plants. The different duration of root dipping showed varied responses, while the 30-min exposure proved to be the most effective with the concentration pattern of $8>16>4>2>0 \mathrm{mg} \mathrm{L}^{-1}$.

Activities of CA and NR: Activities of CA and NR increased under different durations of $\mathrm{ZnO}-\mathrm{NPs}$ treatment (Fig. 3A,B). The 30-min treatment duration proved to be the most effective together with $8 \mathrm{mg}(\mathrm{Zn}-\mathrm{NPs}) \mathrm{L}^{-1}$ and increased the CA activity by $38.5 \%$ and NR activity by $31.2 \%$ in comparison with their respective controls. The minimal effect was noted for the $2 \mathrm{mg}(\mathrm{ZnO}-\mathrm{NPs}) \mathrm{L}^{-1}$ treatment for $30 \mathrm{~min}$ over all the other treatments and duration of root dipping. 


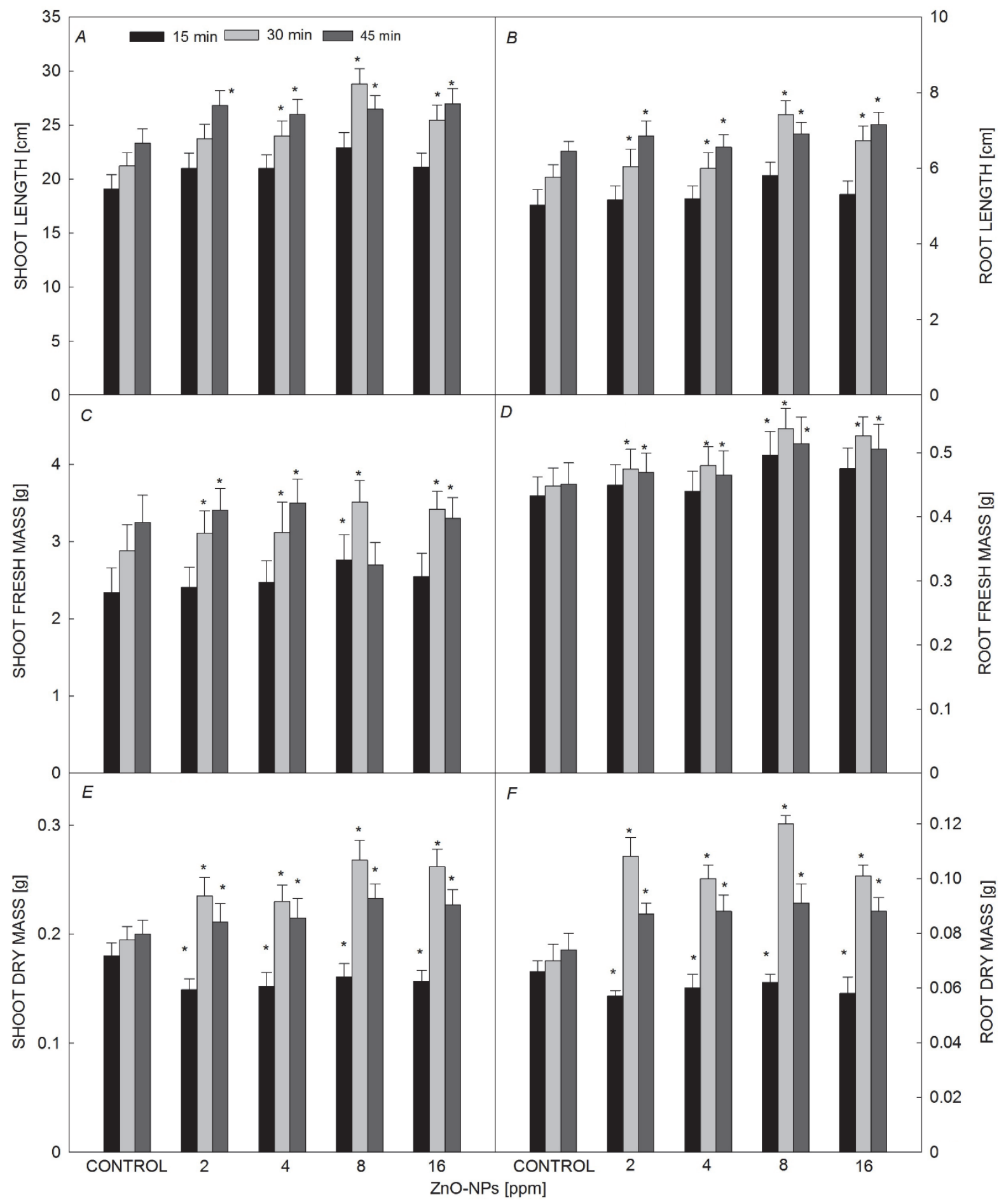

Fig. 1. Effect of ZnO-nanoparticles on the shoot $(A)$ and root length $(B)$, shoot $(C)$ and root fresh mass $(D)$, shoot and $(E)$ root dry mass $(F)$ of tomato plants at 45 DAS. All the data are the mean of five replicates $(n=5)$ and vertical bars show standard errors $( \pm$ SE). $*$ - significant difference between the control of different durations and their respective treatments $(p \leq 0.05)$.

Protein content: Under various $\mathrm{ZnO}-\mathrm{NPs}$ treatments, the treatment of the plants with $\mathrm{ZnO}-\mathrm{NPs}\left(8 \mathrm{mg} \mathrm{\textrm {L } ^ { - 1 }}\right)$ for $30 \mathrm{~min}$ increased the content of proteins in the leaves by $45.0 \%$, compared with their control and other treatments (Fig. 4). Moreover, the increase of protein content depended on the durations and on $\mathrm{ZnO}-\mathrm{NPs}$ concentrations. The pattern for the protein content in the plants treated for 30 min by root dipping in $\mathrm{ZnO}-\mathrm{NPs}$ was in order of $8>16>4>2>0 \mathrm{mg} \mathrm{L}^{-1}$. 


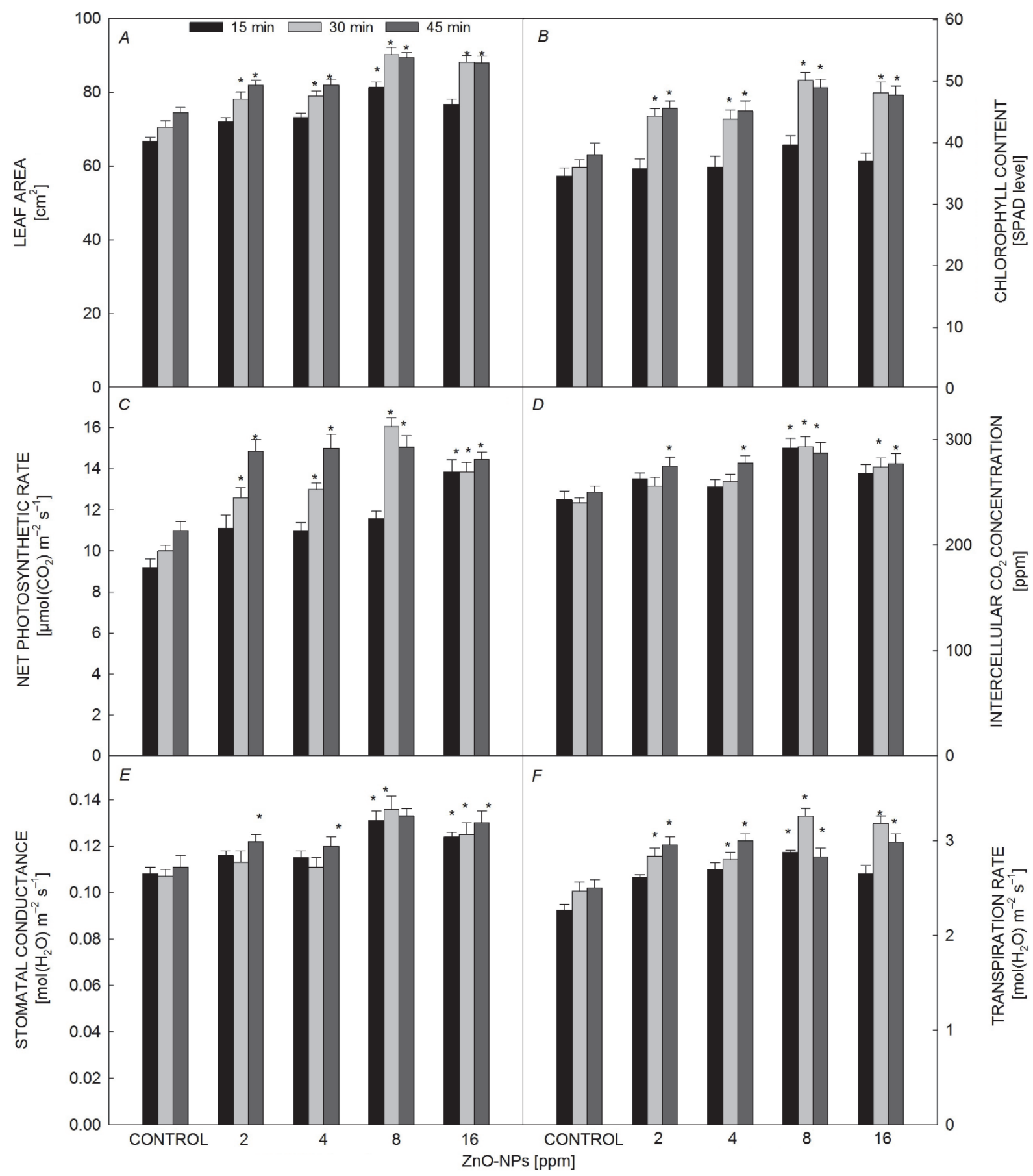

Fig. 2. Effect of nanoparticles (NPs) on the leaf area $(A)$ chlorophyll content $(B)$, net photosynthetic rate $(C)$, internal $\mathrm{CO}_{2}$ concentration $(D)$, stomatal conductance $(E)$, and transpiration rate $(F)$ of tomato plants at 45 DAS. All the data are the mean of five replicates $(n=5)$ and vertical bars show standard errors $( \pm \mathrm{SE}) .{ }^{*}$ - significant difference between the control of different durations and their respective treatments $(p \leq 0.05)$.

Activity of antioxidant enzymes: Our results (Fig. $3 C-E$ ) clearly revealed a significant increase in the activity of antioxidative enzymes (CAT, POX, and SOD) after the treatment of $\mathrm{ZnO}-\mathrm{NPs}$ under various durations of root dipping. Control plants possessed a minimum activity of these enzymes. The maximum activity of these enzymes was noted in the plants treated with $8 \mathrm{mg}(\mathrm{ZnO}-\mathrm{NPs}) \mathrm{L}^{-1}$ for $30 \mathrm{~min}$. The activity of CAT increased by $69.7 \%$, POX by $65.0 \%$, and SOD by $80 \%$ at 45 DAS compared with the control plants. 


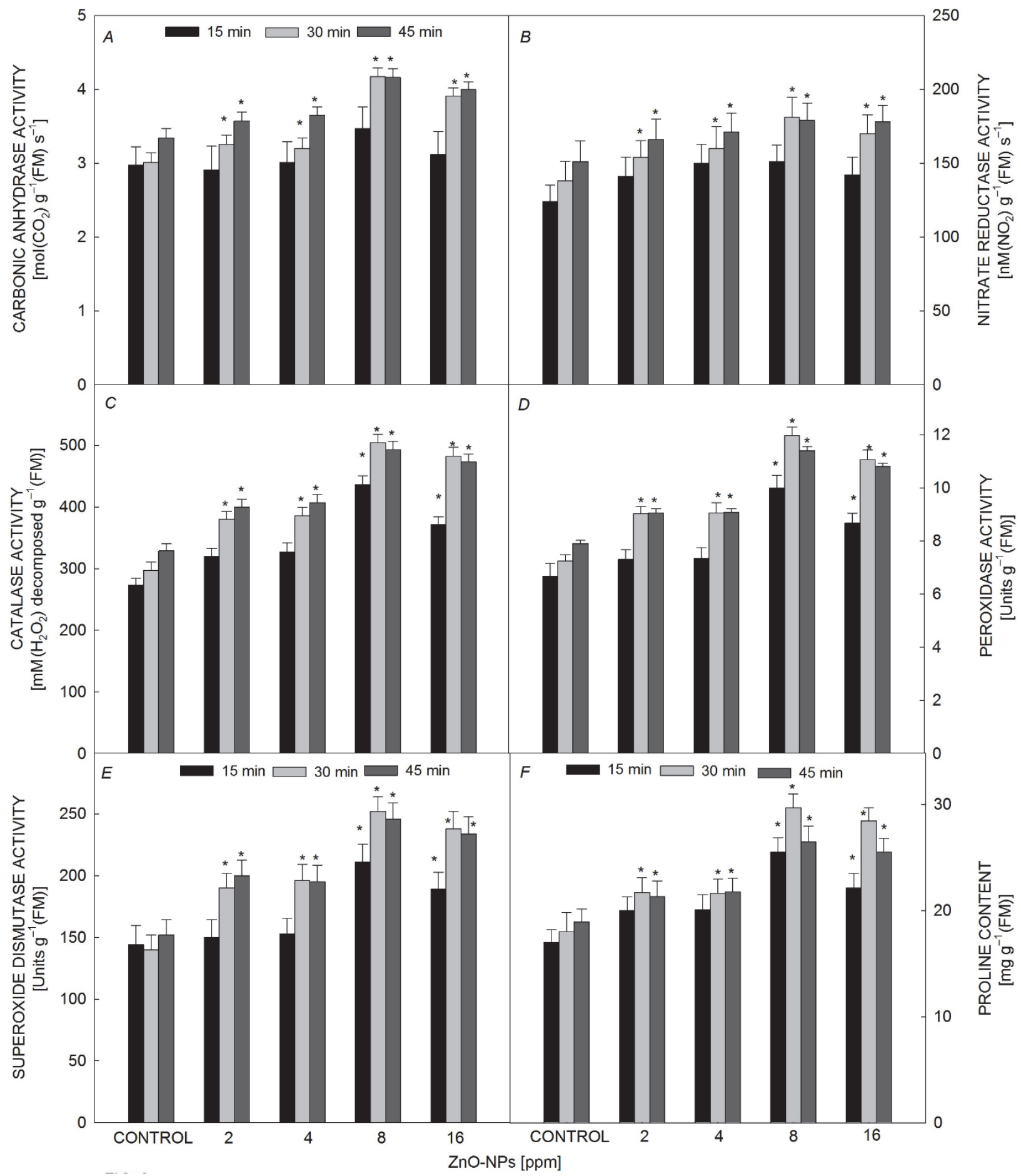

Fig. 3. Effect of nanoparticles (NPs) on the carbonic anhydrase activity $(A)$, nitrate reductase activity $(B)$, catalase activity $(C)$, peroxidase activity $(D)$, superoxide dismutase $(E)$, and proline content $(F)$ of tomato plants at 45 DAS. All the data are the mean of five replicates $(n=5)$ and vertical bars show standard errors $( \pm \mathrm{SE}) .{ }^{*}$ - significant difference between the control of different durations and their respective treatments $(p \leq 0.05)$.

Proline content: The proline content in the leaves of tomato plants increased by the root treatment with $\mathrm{ZnO}$ NPs irrespective of its concentrations and durations. The roots of stock plants dipped in $\mathrm{ZnO}-\mathrm{NPs}\left(8 \mathrm{mg} \mathrm{L}^{-1}\right)$ for 30 min possessed the highest proline content. This treatment increased the proline content by $65.0 \%$ over their control and other treatments. The pattern of proline accumulation in plants with different concentrations after 30 -min root treatment was as follows: $8>16>4>2>0 \mathrm{mg}(\mathrm{ZnO}-\mathrm{NPs}) \mathrm{L}^{-1}$. 


\section{Discussion}

In the present study, treatments of various $\mathrm{ZnO}-\mathrm{NPs}$ concentrations via roots significantly increased the growth biomarkers dependent on the concentration and also duration of the treatment. We believed that nanoparticles induced various morpho-physiological changes in root length, shoot length, root and shoot FM as well as DM, photosynthetic attributes, and biochemical parameters depending on its chemical composition, size, surfacecontact, reactivity, and most significantly on the dose of nanoparticles (Khadakovskaya et al. 2012). Moreover, Zn plays a pivotal role in protecting and maintaining structural stability of cell membranes (Welch et al. 1982, Cakmak 2000). It is also used for protein synthesis, membrane function, cell elongation, and tolerance to environmental stresses (Cakmak 2000, Ajouri et al. 2004). In addition, Prasad et al. (2012) revealed that treatment of groundnut seeds with ZnO-NPs resulted in a significant increase in the germination and other growth biomarkers. Treatments by $\mathrm{ZnO}-\mathrm{NPs}$ showed also significant increase in plant biomass, shoot and root growth, and root area in Solanum lycopersicum (Raliya et al. 2015). Seedling roots of Vigna radiata and Cicer arietinum absorbed $\mathrm{ZnO}-\mathrm{NPs}$ and promoted their length of roots and shoots and its biomass (Mahajan et al. 2011). Release of zinc ions from $\mathrm{ZnO}-\mathrm{NPs}$ has also been demonstrated (Fukui et al. 2012).

Researchers are trying hard to enhance the efficiency of crops by modulating their biochemical and physiological traits. In the present study, 30-min treatment by $8 \mathrm{mg}(\mathrm{ZnO}-\mathrm{NPs}) \mathrm{L}^{-1}$ through roots significantly increased $P_{\mathrm{N}}$ and its related attributes along with $\mathrm{Chl}$ and enhanced activity of CA in tomato plants. Govorov and Carmeli (2007) reported that metal NPs can induce the efficiency of chemical energy production in photosynthetic systems. Moreover, Noji et al. (2011) reported that nanosized silica compound bound to PSII induced stable activity of a photosynthetic oxygen-evolving reaction, indicating the light-driven electron transport from water to the quinone molecules, and they suggested that PSII conjugate might have properties to develop photosensors and artificial photosynthetic system. $\mathrm{SiO}_{2}$-NPs improves photosynthetic rate by improving activity of $\mathrm{CA}$ and synthesis of photosynthetic pigments (Siddiqui et al. 2014, Xie et al. 2012). Govorov and Carmeli (2007) showed that metal NPs induced the efficiency of chemical energy production in photosynthetic systems. The cumulative effect of all these modified processes might improve the photosynthetic machinery in the plants exposed to $\mathrm{ZnO}-\mathrm{NPs}$ $\left(8 \mathrm{mg} \mathrm{L}^{-1}\right)$. These observations are in line with the earlier findings of An et al. (2008) who demonstrated that NPs increased the ascorbate and $\mathrm{Chl}$ contents in the leaves of Asparagus.

In plants exposed to any external stimuli, such as some environmental factors, phytohormones, etc., metal-based NPs induced uncontrolled production of reactive oxygen species (ROS) at different sites of plants. In order to

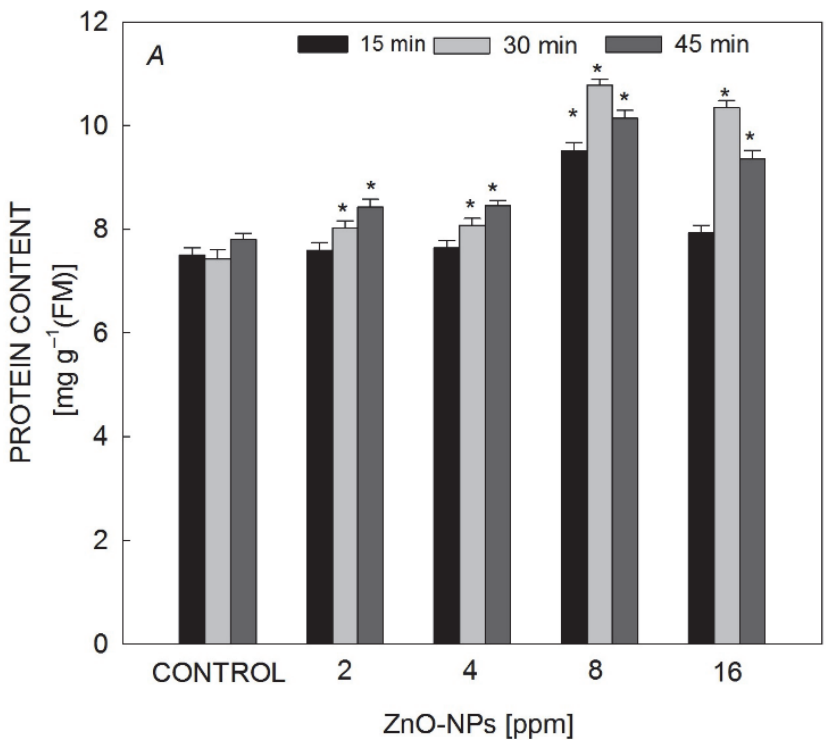

Fig. 4. Effect of nanoparticles (NPs) on the protein content of tomato plants at 45 DAS. All the data are the mean of five replicates $(n=5)$ and vertical bars show standard errors $( \pm \mathrm{SE})$. Asterisks above the bar indicate a significant difference between the control of different durations and their respective treatments $(p \leq 0.05)$.

counter this uncontrolled production of ROS, plants cells and organelles evolved defence system, i.e., antioxidant systems (Gill and Tuteja 2010). SOD is an effective enzymatic antioxidant in all aerobic organisms prone to ROS-mediated oxidative stress. CAT is the enzyme with potential to dismutate directly $\mathrm{H}_{2} \mathrm{O}_{2}$ into $\mathrm{H}_{2} \mathrm{O}$ and $\mathrm{O}_{2}$ and it is crucial for ROS detoxification during unfavourable conditions (Garg and Manchanda 2009). Peroxidase play a pivotal role in protecting cells of higher plants by scavenging $\mathrm{H}_{2} \mathrm{O}_{2}$ in water-water and glutathione-ascorbate cycles (Gill and Tuteja 2010). Moreover, in the present study, the treatment of roots with ZnO-NPs significantly enhanced the antioxidant enzymes (CAT, POX, and SOD; Fig. $3 C, D, E$ ). It is well documented that $\mathrm{Zn}$ plays a critical role in stabilizing the stability of biomembranes and proteins by balancing the scavenging ROS production (Khan et al. 1998). Treatment of Au-NPs improved the antioxidant system in Arabidopsis thaliana and modified the levels of micro RNAs (miRNA) expression that regulates various metabolic processes in plants (Christou et al. 1988). Moreover, Lei et al. (2007) reported that nanosized $\mathrm{TiO}_{2}$ improved antioxidant systems under abiotic stress by declining the accumulation of $\mathrm{H}_{2} \mathrm{O}_{2}$, malondialdehyde content, and increasing activities of SOD, CAT, ascorbate peroxidase, and guaiacol peroxidase in spinach plants. These findings strengthened our finding that exposure of tomato roots to the nanoparticle $\mathrm{ZnO}$ improved the enzymatic antioxidant system (CAT, POX, and SOD; Figs. $3 C-E$ ) to scavenge the excessive ROS. It 
has been also reported $\mathrm{SiO}_{2}$-NPs improved the seed germination in tomato and also enhanced the antioxidant system under stress conditions (Haghighi et al. 2012, Siddiqui et al. 2014). Salama (2012) revealed that treatment of NPs increased growth biomarkers in Brassica juncea plants with the increase of biochemical traits (Chl, carbohydrate, protein content, and antioxidant enzymes). Our study also showed similar findings in terms of the increased protein content and growth biomarkers (Fig. 1) when tomato plants were exposed to $\mathrm{ZnO}-\mathrm{NPs}$.

Proline acts as an nonenzymatic antioxidant that has ability to stabilize the subcellular structures, such as that of proteins and cell membranes, scavenging free radicals and buffering redox potential under stress conditions; it also has the ability of molecular chaperones that protect the integrity of proteins and enhances the activity of different enzymes, such as protection of nitrate reductase under abiotic stress conditions (Szabados and Savoure 2009). Moreover, among various compatible solutes, proline is the only molecule that has been shown to protect plants against singlet oxygen and free radical-induced damages resulting from excess ROS (Alia and Mohanty 1997). These reports support the present observations, where the treatment of $\mathrm{ZnO}-\mathrm{NPs}$ enhanced the accumulation of proline (Fig. $3 F$ ). It has been reported that $\mathrm{ZnO}-\mathrm{NPs}$ supplemented with MS media in banana induced proline synthesis, activity of SOD, CAT, and POX and

\section{References}

Ajouri A., Asgedom H., Becker M.: Seed priming enhances germination and seedling growth of barley under conditions of $\mathrm{P}$ and $\mathrm{Zn}$ deficiency. - J. Plant Nutr. Soil Sc. 167: 630-636, 2004.

Alia., Pardha Saradhi P., Mohanty P.: Involvment of proline in protecting thylakoid membranes against free radical-induce photodamage. - Photochem. Photobiol. B 38: 253-257, 1997.

An J., Zhang M., Wang S. et al.: Physical, chemical and microbiological changes in stored green asparagus spears as affected by coating of silver nanoparticles-PVP. - LWT-Food Sci. Technol. 41: 1100-1107, 2008.

Bernhardt E.S., Colman B.P., Hochella M.F. et al.: An ecological perspective on nanomaterial impacts in the environment. - J. Environ. Qual. 39: 1954-1965, 2010.

Berube D.M., Searson E.M., Morton T.S. et al.: Project on emerging nanotechnologies-consumer product inventory evaluated. - Nanotech. Law Business 7: 152, 2010.

Bradford M.M.: A rapid and sensitive method for the quantitation of microgram quantities of protein utilizing the principle of protein-dye binding. - Anal. Biochem. 72: 248-254, 1976.

Cakmak I.: Role of zinc in protecting plant cells from reactive oxygen species. - New Phytol. 146: 185-205, 2000.

Castiglione M.R., Cremonini R.: Nanoparticles and higher plants. - Caryologia 62: 161-165, 2009.

Chinnamuthu C.R., Boopathi M.P.: Nanotechnology and agroecosystem. - Madras Agri. J. 96: 17-31, 2009.

Christou P., McCabe D.E., Swain W.F.: Stable transformation of soybean callus by DNA coated gold particles. - Plant Physiol. 87: 671-674, 1988. improved a tolerance to biotic stress (Helaly et al. 2014). $\mathrm{SiO}_{2}$-NPs also increased proline accumulation along with Chl content in basil (Ocimum basilicum) (Kalteh et al. 2014, Siddiqui et al. 2014). Therefore, it can be suggested that elevated proline content induced by $\mathrm{ZnO}-\mathrm{NPs}$ may play a significant role in growth and development of plants. However, the mechanism and the reasons for proline accumulation and enhanced antioxidant systems in plants exposed to $\mathrm{ZnO}$-NPs have not been fully investigated. Possible mechanisms behind the nanoparticlemediated changes should be further explored in plants for sustainable agriculture practices.

Conclusions: From our present investigation, we concluded that $\mathrm{ZnO}-\mathrm{NPs}-$ mediated response was concentration- and mode-dependent. Moreover, roots of tomato plants treated with $8 \mathrm{mg} \mathrm{L}^{-1}$ for 30 min showed the most promising response and increased the growth, enhanced photosynthetic efficiency of plants, while other concentrations $\left(2,4\right.$, or $\left.16 \mathrm{mg} \mathrm{L}^{-1}\right)$ and duration (15 or $45 \mathrm{~min}$ ) of $\mathrm{ZnO}-\mathrm{NPs}$ treatment did not show such a promising response. Antioxidant systems and proline accumulation enhanced by $8 \mathrm{mg} \mathrm{L}^{-1}$ for $30 \mathrm{~min}$ provided better ROS protection to plants. Therefore, we believe that root dipping to $\mathrm{ZnO}-\mathrm{NPs}\left(8 \mathrm{mg} \mathrm{L}^{-1}\right)$ could be exploited to improve the productivity and as a potent nano-micronutrient for tomato plants.

Dietz K.J., Herth.: Plant nanotoxicology. - Cell Press 16: 582589, 2011.

Dwivedi R.S., Randhawa N.S.: Evaluation of rapid test for hidden hunger of zinc in plants. - Plant Soil 40: 445-451, 1974.

Fabrega J., Luoma S.N., Tyler C.R. et al.: Silver nanoparticles: behaviour and effects in the aquatic environment. - Environ. Int. 37: 517-531, 2011.

Fukui H., Horie M., Endoh S. et al.: Association of zinc ion release and oxidative stress induced by intratracheal instillation of $\mathrm{ZnO}$ nanoparticles to rat lung. - Chem. Biol. Interact. 198: 29-37, 2012.

García-Sánchez S., Bernales I., Cristobal S.: Early response to nanoparticles in the Arabidopsis transcriptome compromises plant defence and root-hair development through salicylic acid signalling. - BMC Genomics 16: 341, 2015.

Garg N., Manchanda G.: ROS generation in plants: boon or bane? - Plant Biosyst. 143: 81-96, 2009.

Ge Y., Schimel JP., Holden PA.: Identification of soil bacteria susceptible to $\mathrm{TiO}_{2}$ and $\mathrm{ZnO}$ nanoparticles. - Appl. Environ. Microb. 78: 6749-6758, 2012.

Gill S.S., Tuteja N.: Reactive oxygen species and antioxidant machinery in abiotic stress tolerance in crop plants. - Plant Physiol. Bioch. 48: 909-930, 2010.

Govorov A.O., Carmeli I.: Hybrid structures composed of photosynthetic system and metal nanoparticles: plasmon enhancement effect. - Nano. Lett. 7: 620-625, 2007.

Haghighi M., Afifipour Z., Mozafarian M.: The effect of N-Si on tomato seed germination under salinity levels. - J. Biol. Environ. Sci. 6: 87-90, 2012. 
Helaly M.N., El-Metwally M.A., El-Hoseiny H. et al.: Effect of nanoparticles on biological contamination of in vitro cultures and organogenic regeneration of banana. - Aust. J. Crop Sci. 8: 612-624, 2014.

Hewitt E.J.: Sand and Water Culture Methods Used in the Study of Plant Nutrition. Technical Communication No. 22. Pp. 104. Commonwealth Bureau, London 1966.

Jaworski E.G.: Nitrate reductase assay in intact plant tissue. Biochem. Biophys. Res. Co. 43: 1274-1279, 1971.

Kalteh M., Alipour Z.T., Ashraf S. et al.: Effect of silica nanoparticles on basil (Ocimum basilicum) under salinity stress. - J. Chem. Health Risks 4: 49-55, 2014.

Keller A.A., McFerran S., Lazareva A. et al.: Global life cycle releases of engineered nanomaterials. - J. Nano. Res. 15: 1-17, 2013.

Khan S.T., Ahmad J., Ahamed M. et al.: Zinc oxide and titanium dioxide nanoparticles induce oxidative stress, inhibit growth and attenuate biofilm formation activity of Streptococcus mitis. - J. Biol. Inorg. Chem. 21: 295-303, 2016.

Khan T.A., Fariduddin Q., Yusuf M.: Lycopersicon esculentum under low temperature stress: an approach toward enhanced antioxidants and yield. - Environ. Sci. Pollut. R. 22: 1417814188, 2015.

Khan J., Brennan D.M., Bradley N. et al.: 3 Nitrotyrosine in the proteins of human plasma determined by an ELISA method. Biochem. J. 330: 795-801, 1998.

Khodakovskaya M.V., de Silva K., Biris A.S. et al.: Carbon nanotubes induce growth enhancement to tobacco cells. - ACS Nano 6: 2128-2135, 2012.

Lei Z., Mingyu S., Chao L. et al.: Effects of nanoanatase $\mathrm{TiO}_{2}$ on photosynthesis of spinach chloroplasts under different light illumination. - Biol. Trace. Elem. Res. 119: 68-76, 2007.

Lin D., Xing B.: Phytotoxicity of nanoparticles: inhibition of seed germination and root growth. - Environ. Pollut.150: 24350, 2007.

Ma X., Geiser-Lee J., Deng Y. et al.: Interactions between engineered nanoparticles (ENPs) and plants: phytotoxicity, uptake and accumulation. - Sci. Total Environ. 408: 3053-3061, 2010.

Mahajan P., Dhoke S.K., Khanna A.S.: Effect of nano-ZnO particle suspension on growth of mung (Vigna radiata) and gram (Cicer arietinum) seedlings using plant agar method. - J. Nanotechol. 2011: 696535, 2011.

Nair R., Poulose A.C., Nagaoka Y. et al.: Uptake of FITC labeled silica nanoparticles and quantum dots by rice seedlings: effects on seed germination and their potential as biolables for plants. - Fluorescence 21: 2057-2068, 2011.

Noji T., Kamidaki C., Kawakami K. et al.: Photosynthetic oxygen evolution in mesoporous silica material adsorption of photosystem II reaction center complex into $23 \mathrm{~nm}$ nanopores in SBA. - Langmuir 27: 705-713, 2011.
Oancea S., Padureanu S., Oancea A.V.: Growth dynamics of corn plants during anionic clays action. - Lucrări Ştiinţifice 52: 212217, 2009.

Piccinno F., Gottschalk F., Seeger S. et al.: Industrial production quantities and uses of ten engineered nanomaterials in Europe and the world. - J. Nano. Res. 14: 1109, 2010.

Poma A., Giorgio M.L.D.: Toxicgenomics to improve comprehension of the mechanisms underlying responses of in vitro and in vivo systems to nanomaterials: A Review. - Curr. Genomics 9: 571-585, 2008.

Prasad T.N.V.K.V., Sudhakar P., Sreenivasulu Y. et al.: Effect of nanoscale zinc oxide particles on the germination, growth and yield of peanut. - J. Plant Nutr. 35: 905-927, 2012.

Raliya R., Nair R, Chavalmane S et al.: Mechanistic evaluation of translocation and physiological impact of titanium dioxide and zinc oxide nanoparticles on the tomato (Solanum lycopersicum L.) plant. - Metallomics 7: 1584-1594, 2015.

Ramesh M., Palanisamy K., Babu K. et al:: Effects of bulk \& nano-titanium dioxide and zinc oxide on physio-morphological changes in Triticum aestivum Linn. - J. Global Biosci. 3: 415422, 2014.

Salama H.M.H.: Effects of silver nanoparticles in some crop plants, common bean (Phaseolus vulgaris L.) and corn (Zea mays L.). - Int. Res. J. Biotech. 3: 190-197, 2012.

Schwab F., Zhai G., Kern M. et al.: Barriers, pathways and processes for uptake, translocation, and accumulation of nanomaterials in Plants. Critical review. - Nanotoxicology 10: 257278, 2016.

Siddiqui M.H., Al-Whaibi M.H., Faisal M., Al Sahli A.A.: Nanosilicon dioxide mitigates the adverse effects of salt stress on Cucurbita pepo L. - Environ. Toxicol. Chem. 33: 2429-2437, 2014.

Szabados L., Savoure A.: Proline: a multifunctional amino acid. - Trends Plant Sci. 15: 89-97, 2010.

Venkatachalam P., Priyanka N., Manikandan K. et al.: Enhanced plant growth promoting role of phycomolecules coated zinc oxide nanoparticles with $\mathrm{P}$ supplementation in cotton (Gossypium hirsutum L.). - Plant Physiol. Bioch. 110: 118$127,2017$.

Wang Q., Ma X., Zhang W. et al.: The impact of cerium oxide nanoparticles on tomato (Solanum lycopersicum L.) and its implications for food safety. - Metallomics 4: 1105-1112, 2012.

Welch R.M., Webb M.J., Lonegaran J.F.: Zinc in membrane function and its role in phosphorus toxicity. - In: Scaife A. (ed.): Proceedings of $9^{\text {th }}$ International Plant Nutrition. Pp. 710715. Commonw. Agric. Bur., Farnham 1982.

Xie Y., Li B., Zhang Q. et al.: Effects of nano-silicon dioxide on photosynthetic fluorescence characteristics of Indocalamus barbatus McClure. - J. Nanjing Forest Univ. 2: 59-63, 2012. 